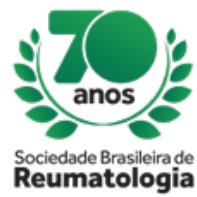

\title{
THE RISK OF CANCER DEVELOPMENT IN SJOGREN SYNDROME
}

Adriana Cristiane Machado (UNISA, SAO PAULO, SP, Brasil), Maria Lúcia Lemos Lopes (ISCMPA/UFCSPA, Porto Alegre, RS, Brasil), Eduardo Rosa (ISCMPA, Porto Alegre, RS, Brasil), Rafael Corandin (ISCMPA/UFCSPA, Porto Alegre, RS, Brasil), Amanda Ayako Minemura Ordinola (UNISA, SAO PAULO, SP, Brasil), André Felipe Gasparini (UNISA, SAO PAULO, SP, Brasil), Juliana Venturini Augusto (UNISA, SAO PAULO, SP, Brasil), Daniela Midori Kamada (UNISA, SAO PAULO, SP, Brasil), Gabriela Mendia Gandarillas (UNISA, SAO PAULO, SP, Brasil), Gabriela Coelho Dutra (UNISA, São Paulo, SP, Brasil), Vírginia Fernandes Moça Trevisani (UNISA/UNIFESP, SAO PAULO, SP, Brasil)

\section{BACKGROUND}

Sjögren Syndrome (SS) is a chronic inflammatory autoimmune condition related to progressive lymphocytic infiltration among exocrine organs, preferably salivary and lachrymal glandules, which has structural and secretory disfunction. The disease has major incidence in women, reaching 9:1 ratio, mainly on 4th - 6th decades. It is classified as primary SS form, characterized by glandular dysfunction; and secondary SS form, associated with other autoimmune diseases. 5-10\% patients will develop non-Hodgkin $B$ cells malign lymphoma, representing an increased risk of 44 times in comparison with general population. The relation between SS and other cancer types in poorly described in the literature. The main of this study was to evaluate the prevalence of cancer in SS population.

\section{MATERIALS AND METHODS}

This is a cohort, multicentric, longitudinal, prospective study that followed 162 female patients between 18-73 years old diagnosed with SS by the American-European Consensus Criteria (2002) from 2014 to 2019. The disease activity was evaluated by EULAR Sjögren's Syndrome Disease Activity Index (ESSDAI). Scores between 0-5 represents low activity, 5-15 moderated and more than 15 severe.

\section{RESULTS}

162 patients with SS disease, which 11 patients developed cancer (four breast cancer, one papillary thyroid carcinoma, one lung cancer, one uterine cancer, one gastric cancer, two lymphomas, one spinocellular carcinoma in situ). The age average was 48,67 years with standard deviation (SD) of 12,66 and in the cancer sample was 51,81 years, SD of 14,64 . The cancer incidence in the SS population studied was $6,79 \%$ and had major prevalence in the white ethnic $(72,72 \%)$. Meanwhile, the general population demonstrated an incidence of $0,5 \%$. In the studied population, 59,87\% were white, $8,64 \%$ Afrodescent, $29,62 \%$ Hispanic and $4,32 \%$ Asian. The ESSDAl score had an average of 7,3 (moderated activity); and in the cancer population of 7,54 ( $36,36 \%$ low activity, $54,54 \%$ moderated and $9,09 \%$ severe). Both cancer and SS population presented the articular domain as the most prevalent $(45,45 \%$ in the cancer population). The second most common domain affected by the patients were glandular, cutaneous and biological, representing $36,36 \%$. The cutaneous was the most severe scored domain.

\section{CONCLUSION}

According to the DATASUS of 2013 , the notificated neoplasias in general population was 19,210 cases in 3.477 .439 of female habitants, corresponding to $0,5 \%$. Incidence of neoplasia represents $6,79 \%$ in the elected sample of the study. Therefore, the incidence of cancer is higher in the SS population. 